\title{
Acquisition, Development, and Maintenance of Online Poker Playing in a Student Sample
}

\author{
RICHARD T.A. WOOD, Ph.D., MARK D. GRIFFITHS, Ph.D., and JONATHAN PARKE, B.Sc.
}

\begin{abstract}
To date there has been very little empirical research into Internet gambling and none relating to the recent rise in popularity of online poker. Given that recent reports have claimed that students may be a vulnerable group, the aim of the current study was to establish basic information regarding Internet poker playing behavior among the student population, including various motivators for participation and predictors of problematic play. The study examined a self-selected sample of student online poker players using an online survey $(n=$ 422). Results showed that online poker playing was undertaken at least twice per week by a third of the participants. Almost one in five of the sample (18\%) was defined as a problem gambler using the DSM-IV criteria. Findings demonstrated that problem gambling in this population was best predicted by negative mood states after playing, gender swapping whilst playing, and playing to escape from problems.
\end{abstract}

\section{INTRODUCTION}

$\mathbf{T}$ O DATE there has been very little empirical research into Internet gambling. Despite the paucity of current research, there is a strong foundation for speculating on the potential hazards of Internet gambling. For instance, the use of virtual cash, unlimited and convenient accessibility, and the solitary nature of gambling on the Internet are all potential risk factors for the development of problem gambling. ${ }^{1-3}$

As far as the authors are aware, there have been only three published prevalence-type studies specifically investigating Internet gambling. A prevalence survey in the United Kingdom examining Internet gambling found that, of the 2,098 random people surveyed (918 male and 1,180 female), only 495 of them $(24 \%)$ were Internet users. ${ }^{4}$ The results showed that not one person gambled regularly on the Internet (i.e., once a week or more) and that only
$1 \%$ of the Internet users were occasional Internet gamblers (i.e., less than once a week). There was no evidence from this study that Internet gambling was in any way problematic and/or addictive. However, data from this study was carried out when Internet gambling was in its infancy, and the situation has developed considerably since then.

In Canada, a prevalence study of Internet gambling among Ontario adults collected data by using a random telephone survey of 1,294 Ontario adults. ${ }^{5}$ Overall, 5.3\% had gambled on the Internet during the past 12 months. Although women were more likely to gamble online than males $(6.3 \%$ versus $4.3 \%$ ), the difference was not statistically significant. There were no dominant age, regional, educational, or income differences. The study did not examine any aspects of problem gambling.

In the United States, a survey was carried out examining gambling among 389 self-selected individuals from university health and dental clinics. ${ }^{6}$ Em- 
bedded within the questions was the South Oaks Gambling Screen (SOGS). The study found that $90 \%$ of the sample had gambled within the last year and $70 \%$ had gambled within the previous 2 months of the survey. It was also reported that 31 individuals $(8 \%)$ had gambled on the Internet at some point in their lives and 14 of them (3.6\%) engaged in Internet gambling weekly. Mean scores on the SOGS showed that the Internet gamblers had significantly higher scores than the non-Internet gamblers $(7.8$ compared to 1.8). The authors concluded that Internet gamblers were significantly more likely to be problem gamblers than non-Internet gamblers. However, there were many limitations to the study, the major one being the use of a self-selected sample in dental waiting rooms.

Over the past few years, there has been a worldwide explosion in the participation and the popularity of online poker (particularly games such as "No Limit Texas Hold 'em"). Possible precipitating factors for this trend might include (i) the increasing number of celebrities endorsing and playing poker, (ii) poker being shown via television (both terrestrial and cable channels) and on the Internet, (iii) players can learn to play for free, (iv) players can play for low stakes (as low as one cent), and (v) individuals have 24-h access and can play at any time, any day via the Internet.

In the United Kingdom, it has been observed that the two fastest growing forms of online gambling are online poker and online betting exchanges, and it has been speculated there are three main reasons for the growth in these two particular sectors. ${ }^{3}$ Firstly, they provide excellent financial value for the gambler; there is no casino house edge or bookmakers' mark-up on odds. Secondly, gamblers have the potential to win because there is an element of skill in making their bets. Thirdly, gamblers are able to compete directly with and against other gamblers instead of gambling on a pre-programmed slot machine or making a bet on a roulette wheel with fixed odds. However, recent research has shown that one of the potential downsides to increased competition is that problem gamblers are significantly more likely to be competitive when compared to nonproblem gamblers. ${ }^{7}$

It is speculated that the introduction and popularity of online poker may be an issue for concern regarding problematic gambling behavior. There have been recent press reports in the United Kingdom (and elsewhere) that large numbers of university students may be experiencing financial problems as a direct result of playing online poker. Reasons for participation in online poker may include its wide availability to students who all have familiarity with using the Internet and students' increased freedom upon leaving home.

The aim of the current study was to establish basic information regarding Internet poker-playing behavior among the student population, including various motivators for participation, monies won and lost, levels of problem gambling, and predictors of problematic play (i.e., an examination of the psychosocial correlates of online poker play in a student sample). This was not a prevalence study as all data collected came from a self-selected sample of students, all of whom played online poker. However, as will be argued below, we believe that the sample is a representative sample of available student poker players who play online.

\section{METHODS}

\section{Participants}

A total of 422 participants took part in the study (362 males and 60 females) and had a mean age of 21 years (18-47 years; $S D=3.4$ years). Participants were students and self-defined as online poker players. They were recruited from a university in the Midlands area of the United Kingdom. The university attracts students from across the United Kingdom, and participants originated from a wide variety of cities nationally.

\section{Design, materials, and procedure}

An online survey was constructed using Autoform, an in-house survey generating tool (http://ess. ntu.ac.uk/autoform/). The survey contained 67 closed questions, including the DSM-IV diagnostic criteria for pathological gambling, and four openended questions. Questions related to frequency of play, average wins and losses, and experience relating to a variety of gambling activities. Specific questions about online poker playing related to motivations, strategies, concerns, mood states before and after playing, and perceptions of the activity. Data were collected online as it has been argued that this medium is particularly well suited for investigating online gaming behavior. ${ }^{8}$

Approximately 10,000 students were contacted via a university-wide email specifically asking for online poker players to take part in the study. Given that press reports claim about $5 \%$ of the U.K. population has engaged in online poker, it was estimated that approximately 500 students across the university may have engaged in online poker. Given that 422 participants responded, it was assumed that the sample obtained was a reasonably repre- 
sentative sample of available student online poker players. They were informed that all responses would be confidential and that their email address would not be passed onto anyone else. Participants who wanted to take part followed a link that led them to the online questionnaire, where further instructions were given on how to complete it. Once the questionnaire was completed, the participants pressed "Send," and their responses were automatically sent to the research team.

\section{RESULTS}

Gambling frequency, money won/lost, and other types of gambling

Results indicated that online poker players varied in their frequency of online poker play. Around a third of online poker players engaged in the activity rarely $(32.9 \%)$, a third occasionally $(37.9 \%)$, and a third frequently $(22.3 \%$ a few days a week and $6.9 \%$ every day; Table 1 ).

Overall, the most frequent amount that participants reported winning per month playing online poker was $£ 10-50(46.9 \%)$, followed by less than $£ 10$ (38.6\%), £51-100 (6.9\%), £101-200 (4.3\%), £201-500 $(0.9 \%)$, and more than $£ 500(2.4 \%)$. The most frequent amount that participants reported losing per month playing online poker was less than $£ 10$ (53.3\%), followed by $£ 10-50(38.2 \%), £ 51-100(5.0 \%)$, $£ 101-200(2.1 \%), £ 201-500(0.7 \%)$, and more than $£ 500(0.7 \%)$.
Online poker players also engaged in a wide variety of other gambling behaviors. The most frequent of these were sports betting $(16.4 \%$ a few times a week and $4.3 \%$ every day), slot machine gambling $(11.6 \%$ a few times a week and $1.4 \%$ every day), playing the lottery $(10.2 \%$ a few times a week and $0.9 \%$ every day), gambling on other non-online card games $(11.8 \%$ a few times a week and $0.2 \%$ every day), and other online card games $(8.3 \%$ a few times a week and $0.9 \%$ every day; for overall frequencies by type of gambling, see Table 1).

Acquisition of online poker playing and reasons for playing

All participants were asked when they first started playing online poker. Results showed that two-thirds $(66 \%)$ had started playing in the 12 months preceding participation in the survey. Just less than a fifth of the sample had been playing online poker for over one and a half years $(18.9 \%)$. The majority of participants $(62 \%)$ reported that they first started playing online poker because their friends were playing, 23\% because they watched poker on television, $11.4 \%$ because they were offered a free go by a spam email or through a pop up, and $3.6 \%$ because they had responded to an advertisement.

Online poker players gave many different reasons why they engaged in the activity, including relaxation ( $13 \%$ always/frequently, $56 \%$ rarely/ never), excitement (51\% always/frequently, $17 \%$ rarely/never), winning money (50.5\% always/fre-

Table 1. Frequency of Play on All Gambling Activities by Participants $(N=422)$

\begin{tabular}{|c|c|c|c|c|c|}
\hline Gambling activity & Never & $\begin{array}{c}\text { Rarely } \\
\text { (few times a } \\
\text { year) }\end{array}$ & $\begin{array}{c}\text { Occasionally } \\
\text { (few times a } \\
\text { month) }\end{array}$ & $\begin{array}{c}\text { Frequently } \\
\text { (few times a } \\
\text { week) }\end{array}$ & $\begin{array}{c}\text { Every } \\
\text { day }\end{array}$ \\
\hline Online poker & $0 \%$ & $32.9 \%$ & $37.9 \%$ & $22.3 \%$ & $6.9 \%$ \\
\hline $\begin{array}{l}\text { Offline poker (casino } \\
\text { or with friends) }\end{array}$ & $15.9 \%$ & $31.3 \%$ & $39.1 \%$ & $13.0 \%$ & $0.7 \%$ \\
\hline National lottery & $20.6 \%$ & $34.1 \%$ & $34.1 \%$ & $10.2 \%$ & 0.9 \\
\hline $\begin{array}{l}\text { Other card games } \\
\text { (not online) }\end{array}$ & $23.2 \%$ & $31.8 \%$ & $32.9 \%$ & $11.8 \%$ & $0.2 \%$ \\
\hline Sports betting & $22.5 \%$ & $27.5 \%$ & $29.4 \%$ & $16.4 \%$ & $4.3 \%$ \\
\hline Slot machines & $27.7 \%$ & $31.0 \%$ & $28.2 \%$ & $11.6 \%$ & $1.4 \%$ \\
\hline Scratchcards & $40.8 \%$ & $38.2 \%$ & $18.2 \%$ & $2.1 \%$ & $0.7 \%$ \\
\hline Other online card & $44.5 \%$ & $28.0 \%$ & $18.2 \%$ & $8.3 \%$ & $0.9 \%$ \\
\hline $\begin{array}{l}\text { Virtual roulette } \\
\text { (betting shops) }\end{array}$ & $58.3 \%$ & $25.4 \%$ & $12.8 \%$ & $3.3 \%$ & $0.2 \%$ \\
\hline Roulette (in casino) & $50.0 \%$ & $31.3 \%$ & $15.2 \%$ & $3.6 \%$ & $0 \%$ \\
\hline Spread betting & $76.8 \%$ & $14.7 \%$ & $7.6 \%$ & $0.7 \%$ & $0.2 \%$ \\
\hline Bingo & $80.3 \%$ & $16.4 \%$ & $2.6 \%$ & $0.5 \%$ & $0.2 \%$ \\
\hline
\end{tabular}


quently, $24 \%$ rarely, never), socializing ( $8 \%$ always / frequently, $76 \%$ rarely/never), escaping problems (6\% always/frequently, $82 \%$ rarely/never), relieving boredom ( $28 \%$ always/frequently, 33\% rarely / never), developing skills ( $27.5 \%$ always / frequently, $45 \%$ rarely/never), and feeling lucky ( $7 \%$ always/ frequently, $72.5 \%$ rarely/never). More players reported that online poker was mainly a game of skill $(38 \%)$ than mainly a game of chance $(32 \%)$, or that it was equally skill and chance based (30\%).

\section{Gender swapping}

More female players ( $20 \%$ of females) reported swapping gender when playing compared to males $(12 \%)$, although this gender difference was not statistically significant. Typical reasons that female participants gave as to why they did this were that they believed males would not take them seriously if they knew they were playing against a woman. It also gave them a greater sense of security as a lone woman in a predominantly male arena.

Males agreed that females were not taken as seriously as males, but believed that pretending to be female would give them a strategic psychological advantage. Different male players reported that the advantage arose for one of two reasons. One suggested reason was that they believed other male players were less aggressive, in their play, toward female players. The other reason given by some males was that they believed other male players felt that they could intimidate female players, and so they could lure those males into a false sense of security, thus allowing them to potentially win more money.

\section{Problem gambling in online poker players}

Results indicated that $18 \%(n=76)$ of the respondents (66 male; 10 female) were classified as probable pathological gamblers (i.e., they endorsed four or more of nine categories of the DSM-IV criteria for pathological gambling). A further $30 \%$ ( $n=$ 126) may have had some gambling problems as they endorsed two or three categories of the DSM-IV criteria, and $52 \%(n=220)$ were non-problem-gamblers on the basis of endorsing none or one of the categories of DSM-IV criteria. Statistical analysis later in this section is performed on these three subgroups of online poker players. For the purposes of this paper, the three groups are operationally defined, according to how they scored on the DSM-IV category criteria, as social gamblers (SGs), gamblers with some problems (SPGs), and problem gamblers (PGs).

There was no significant association between the severity of the gambling behavior, as measured by the DSM-IV, and when participants reported that they first started playing online poker $\left(\chi^{2}=9.2\right.$, d.f. $=10, p=0.513)$. As expected, there was a significant association between the severity of the gambling behavior, as measured by the DSM-IV, and the frequency of online poker playing behavior $\left(\chi^{2}=\right.$ 922.9, d.f. $=6, p<0.001$; Table 2).

There was a significant association between the severity of the gambler (as measured by the number of categories endorsed on the DSM-IV criteria) and whether or not they believed they would be more likely to take part in other online gambling since playing online poker $\left(\chi^{2}=47.2\right.$, d.f. $=8, p<$ $0.001)$. Fifty percent of the gamblers who reported some problems indicated they would be most likely to play other online games, compared to $45 \%$ of problem gamblers, and $27 \%$ of social gamblers. Using the stepwise method of multiple regression a significant model emerged $\left(F_{12,398}=31.7, p<\right.$ 0.0001 ; adjusted $\left.R^{2}=0.473\right)$. Significant variables that predicted problem gambling, as measured by DSM-IV scores included increased negative mood

Table 2. Association between Frequency of Online Poker Play AND DSM-IV SCORE IN PARTICIPANTS $(N=422)$

\begin{tabular}{lcccc}
\hline & $\begin{array}{c}\text { Rarely (once or } \\
\text { twice a year) }\end{array}$ & $\begin{array}{c}\text { Occasionally } \\
\text { (few times } \\
\text { year) }\end{array}$ & $\begin{array}{c}\text { Frequently } \\
\text { (few times a } \\
\text { week) }\end{array}$ & Every day \\
\hline $\begin{array}{c}\text { Social gamblers } \\
(n=220)\end{array}$ & $38.2 \%$ & $40.9 \%$ & $16.8 \%$ & $4.1 \%$ \\
$\begin{array}{c}\text { Gamblers with } \\
\text { some problems } \\
(n=126)\end{array}$ & $23.0 \%$ & $40.5 \%$ & $25.4 \%$ & $11.1 \%$ \\
$\begin{array}{c}\text { Problem gamblers } \\
(n=76)\end{array}$ & $34.2 \%$ & $25.0 \%$ & $32.9 \%$ & $7.9 \%$ \\
\hline
\end{tabular}


Table 3. Predictors of Problem Gambling in Online PoKer Players $(N=422)$ BASEd ON DSM-IV SCORES

\begin{tabular}{lrc}
\hline Predictor variable & Beta & $p$ \\
\hline Feel happy after playing (feel less happy) & -0.353 & $<0.001$ \\
Gender swap when playing (more likely to) & -0.275 & $<0.001$ \\
Play to escape & 0.172 & $<0.001$ \\
Play roulette in casino & 0.116 & $<0.006$ \\
Chance versus skill & 0.139 & $<0.001$ \\
Play virtual roulette (in betting shops) & 0.126 & $<0.002$ \\
Feel satisfied after play (feel less satisfied) & -0.141 & $<0.002$ \\
Personal skill rating & 0.134 & $<0.001$ \\
Feel guilty after playing & 0.121 & $<0.002$ \\
Play in casino tournaments & 0.082 & $<0.043$ \\
Play cards with friends (less likely to) & -0.129 & $<0.003$ \\
Play privately for cash & 0.094 & $<0.036$ \\
\hline
\end{tabular}

states after playing (i.e., unhappy, dissatisfied, guilty) playing to escape problems, increased gender swapping (e.g., males pretending to be females when playing), the belief that online poker was about both chance and skill equally, rating themselves as having an average level of skill, increased playing of virtual roulette in betting shops, increased playing of roulette in casinos, increased playing of private card games for cash, and decreased playing socially with friends. These and other significant predictors are outlined in Table 3.

The reasons for playing online poker differed in frequency across the three subgroups (Table 4). Gambling for excitement and to win money were the most popular reasons given for playing online poker across all categories of players (SGs, SPGs, and PGs). This motivation was most apparent among SPGs. However, it should be noted that PGs were significantly more likely than other gamblers to report gambling to escape from problems, and playing because they felt lucky. Problem gamblers were most likely to report that they had pretended to be a different gender when playing online poker $(38 \%)$, compared to gamblers with some problems $(9.5 \%)$ and social gamblers $(7 \%)$.

There were significant differences in the amounts that were reported as won each month according to the severity of gambling behavior $\left(\chi^{2}=31.27\right.$, d.f. $=$ $12, p<0.002)$. Problem gamblers reported winning more per month than either SPGs, or SGs. There were also significant differences in the amount of money that were reported as lost each month according to the severity of gambling behavior $\left(\chi^{2}=\right.$ 64.34 , d.f. $=12, p<0.001)$. Problem gamblers re-

Table 4. Reasons for Playing Online Poker by Participants $(N=422)$

\begin{tabular}{|c|c|c|c|c|c|c|c|c|}
\hline \multirow[b]{2}{*}{$\begin{array}{l}\text { Reasons for playing } \\
\text { online poker }\end{array}$} & \multicolumn{2}{|c|}{$\begin{array}{l}\text { Social gamblers } \\
\quad(n=220)\end{array}$} & \multicolumn{2}{|c|}{$\begin{array}{l}\text { Gamblers with some } \\
\text { problems }(n=126)\end{array}$} & \multicolumn{2}{|c|}{$\begin{array}{l}\text { Probable pathological } \\
\text { gamblers }(n=76)\end{array}$} & \multirow[b]{2}{*}{$\begin{array}{l}\text { Chi } \\
\text { Square df }\end{array}$} & \multirow[b]{2}{*}{$\mathrm{p}$} \\
\hline & $\begin{array}{l}\text { Rarely or } \\
\text { occasionally }\end{array}$ & $\begin{array}{l}\text { Frequently } \\
\text { or always }\end{array}$ & $\begin{array}{l}\text { Rarely or } \\
\text { occasionally }\end{array}$ & $\begin{array}{l}\text { Frequently } \\
\text { or always }\end{array}$ & $\begin{array}{l}\text { Rarely or } \\
\text { occasionally }\end{array}$ & $\begin{array}{l}\text { Frequently } \\
\text { or always }\end{array}$ & & \\
\hline To relay & 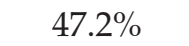 & 1270 & 1 & 1420 & & 1050 & 14.1398 & 0.078 \\
\hline For & 4 & & & & & & 39.2188 & $0.001^{*}$ \\
\hline To win money & $43.7 \%$ & $38.7 \%$ & $28.5 \%$ & $67.4 \%$ & $23.6 \%$ & $56.6 \%$ & 40.7028 & $0.001^{*}$ \\
\hline ialize & $35.0 \%$ & $8.2 \%$ & $46.9 \%$ & $5.6 \%$ & $43.5 \%$ & $10.6 \%$ & 10.3508 & 0.241 \\
\hline To escape problems & $20.5 \%$ & $3.2 \%$ & $33.4 \%$ & $6.4 \%$ & $38.2 \%$ & $15.8 \%$ & 40.6358 & $0.001^{*}$ \\
\hline To relieve boredom & $61.0 \%$ & $24.6 \%$ & $54.0 \%$ & $36.5 \%$ & $51.3 \%$ & $23.6 \%$ & 14.5548 & 0.068 \\
\hline To develop skills & $47.8 \%$ & $23.6 \%$ & $38.95 \%$ & $37.3 \%$ & $28.9 \%$ & $22.4 \%$ & $22.434 \quad 8$ & $0.004^{*}$ \\
\hline Because I feel lucky & $35.0 \%$ & $3.6 \%$ & $47.6 \%$ & $6.4 \%$ & $36.9 \%$ & $15.8 \%$ & 26.7358 & $0.001^{*}$ \\
\hline
\end{tabular}

*Statistically significant. 
ported losing more money per month than either SPGs or SGs. Problem gamblers were significantly more likely to report always or frequently spending more than they intended when playing online poker $(30.2 \%)$, followed by SPGs $(7.1 \%)$, and SGs $(2.3 \%$; $\chi^{2}=86.5$, d.f. $\left.=8, p<0.001\right)$.

\section{DISCUSSION}

This study attempted to examine the acquisition, maintenance, and development of online poker playing in a self-selected group of students (and therefore cannot be considered a prevalence study). However, the sample is likely to be a reasonably representative sample of online poker players in a student population if the prevalence of student online poker gambling matches that of the general U.K. population (i.e., $5 \%$, based on press reports) as just under $5 \%$ of all targeted students responded to the survey on the basis that they had played online poker. The study identified that almost half of the sample could be classified as exhibiting some gambling problems $(\mathrm{SPG}=30 \%$; $\mathrm{PG}=18 \%$ ), although it should be noted that the sample was drawn from a self-selected sample of online poker players and not the general population. However, considering that all the participants were students at just one U.K. university, this could still be considered a somewhat worrying figure. Furthermore, online poker playing appeared to be just one of a number of gambling activities that most participants engaged in on a regular basis. With almost $30 \%$ of students from this sample playing poker at least twice a week, the speculation that online poker playing is a popular pastime amongst students was confirmed.

It was also interesting that more of the players in our sample viewed online poker as mostly a game of skill rather than either mostly chance based or an equal combination of both skill and chance. If students enjoy playing poker and feel that they possess the requisite skills to be successful, then one might expect that they will attempt to use this pastime, at least in part, as an attempt to resolve their financial constraints. Gambling to win money was the most common reason claimed by participants for playing poker across all categories of player (SG, $S P G$, and PG). Further research is needed to examine in detail the perceptions of skill and control in relation to online poker playing.

Online poker playing appears to be an important social activity for some students, and $62 \%$ of the students in our study claimed that they started playing through an introduction to the game by friends.
Exposure to online poker playing may be relatively frequent compared to non-student populations. Also, it is likely that students have more familiarity with using the Internet than the general population, and it is also that case that university students in the United Kingdom are much more likely to have Internet access at home than the general population. ${ }^{9}$ Therefore, it could be concluded that the acquisition of poker playing behavior is more likely among a student population than the general population due to factors such as accessibility, social influence, and financial motivation.

It was interesting to note the practise of gender swapping and the different motivations of those male and females who did this. Whereas, for males it was a tactical move to give them a strategic advantage, for females it was much more about acceptance or privacy in what they perceived to be a male-dominated environment. Similar findings have been reported in relation to online game playing. ${ }^{10}$ Data from this study highlights that these tactics are also used in online poker games, although it may be the traditional male domination of this activity (i.e., poker), rather than the medium (i.e., the Internet), that precipitates gender swapping in females. It has been argued that the Internet would make gambling more acceptable for women because the Internet is seen as less alienating and stigmatising medium when compared to gambling environments such as casinos and betting shops. ${ }^{5}$

As expected, those who exhibited gambling problems reported that they played more frequently than social gamblers. However, more participants who reported some gambling problems (two to three categories on DSM-IV) reported playing online poker everyday compared to problem gamblers. Also as expected, those who were classified as problem gamblers were more likely to report losing larger sums of money than any of the other gamblers. Problem gamblers were more likely than social gamblers to also play roulette in a casino, play virtual roulette in betting shops, play poker in casino tournaments, and play cards privately for cash. However, they were less likely to play poker socially with friends.

The best predictor of problem gambling in the study was a negative correlation with feeling happy after playing although this was most likely a consequence of the gambling itself. Other affective predictors were reduced satisfaction after playing, and feeling guilty after playing. Although these negative states were consequences of gambling, they could conceivably facilitate a need to modify mood (hence continued gambling), either in response to underlying psychological states (e.g., depression, 
anxiety) and/or in direct response to increased losses (i.e., cognitive regret and chasing). This would then explain why gambling to escape from problems was also another major predictor of problem gambling behavior in the study. Previous studies have noted how adolescent problem gamblers use their gambling behavior to dissociate and escape from problems in their lives. ${ }^{11,12}$

Overall, the findings suggest that problem gambling is frequently rooted in a response to "block out" negative mood states, as suggested by Jacob's General Theory of Addictions. ${ }^{13}$ It also indicates that a sub-group of emotionally vulnerable problem gamblers use their gambling behavior as a means of modifying mood states and/or to meet specific psychological needs, as noted by the "pathway model" of problem gambling. ${ }^{14}$ More recently, these influences have been theoretically integrated and explained further through a grounded theory of problem gambling as an escape-based coping strategy. ${ }^{15}$

Those with some symptoms of problem gambling were most likely to report that online poker playing was purely a game of skill rather than chance. Problem gamblers were the least likely sub-group to report that poker was a game of mainly skill, and this may reflect their experiences of losing more money playing online poker than those with less severe problems, or no problems. Similarly, problem gamblers were least likely to rate themselves as above average skill when playing online poker, and again this could relate to the realization that their playing had resulted in significant financial losses. Therefore, it appeared that those with the most severe gambling problems had the least misperceptions about both the nature of the activity and their own skill rating. Therefore, it may be that such misperceptions only facilitate the onset of problem gambling and that over time, and as the severity of gambling behavior increases, so the gambler realizes, after sustaining considerable losses, that online poker is not as skill based as they originally thought. This realization may also extend to recognition that they are not as skilled at playing online poker as they originally thought. Despite the fact that PGs reported winning more money than other gamblers, they also reported losing the most as well.

An alternative explanation could be that the PGs and SPGs were in fact qualitatively different types of gamblers, rather than in a quantitatively different developmental phase of their gambling career. For example, perhaps some of the SPGs were actually more skilled gamblers than the PGs and that is why they lost less money. The reasons why the SPGs confirmed two or three categories on the DSM-IV could relate to features such as preoccupation, chasing losses, and needing to gamble with more and more money to achieve a desired level of excitement. In themselves, these categories could simply indicate that a person is a very keen online poker player rather than someone who has problems. Unless they are experiencing some kind of problem, then it is conceivable that there is no problem, particularly if they are not actually losing large sums of money. This ambiguity is a general weakness of research in which problem gambling is defined and understood through purely quantitative measures. Further qualitative research of online poker players is needed to examine in detail the phases of their gambling problem. Furthermore, longitudinal research is needed to determine how many online poker players pass through a distinct stage whereby their behavior can be accurately understood as "somewhat problematic."

There were significant differences in the reasons given for playing online poker depending upon the severity of the participant's gambling problems. SPGs were more likely than either SGs or PGs to report that they played to win money. PGs were more likely than other gamblers to report that they played to escape problems, and this could indicate a realization that winning money was not (or was no longer) their primary motivation to continue gambling. Similarly, SPGs were most likely to report that they found online poker exciting. PGs may have developed a tolerance to the excitement that they first experienced when gambling, which would explain why it was not as exciting for them. However, PGs were more likely than SPGs or SGs to report that they played online poker when they felt lucky, which could conceivably contribute to an illusion of control over their gambling behavior. Therefore, in the face of continued losses, PGs may account for their losing as "bad luck," considering it to be a streak that will eventually change for the better. Similarly, the finding that PGs were more likely to swap gender whilst playing could also add to increased feelings of control over the game, at least for male gamblers who reported gender swapping as a tactic by which to gain a strategic advantage over other players.

Overall, the study found a relatively high level of problem gambling amongst student online poker players. This is worrying given both the increasing levels of student debts in the United Kingdom, and the rate at which online gambling is developing around the world. This is most likely due to the social acceptability of this type of gambling, which is promoted through televised tournaments and often involves celebrity players, together with the 24-h, 
seven-days-a-week availability, and the belief that this is predominantly a game of skill that can be mastered. Further research is needed to examine student attitudes and those of the general public to these forms of gambling. Furthermore, greater awareness needs to be promoted about the relative danger that this type of gambling poses for individuals and how gambling, like other mood-altering activities and substances, can lead to further problems when relied upon to alter mood states and/or escape from problems.

\section{REFERENCES}

1. Griffiths, M.D., \& Parke, J. (2002). The social impact of internet gambling. Social Science Computer Review 20:312-320.

2. Griffiths, M.D. (2003). Internet gambling: issues, concerns and recommendations. CyberPsychology $\mathcal{E} B e-$ havior 6:557-568.

3. Griffiths, M.D., Parke, A., Wood, R.T.A., et al. (2006). Internet gambling: an overview of psychosocial impacts. Gaming Research and Review Journal 27:27-39.

4. Griffiths, M.D. (2001). Internet gambling: preliminary results of the first UK prevalence study. Journal of Gambling Issues. Available at: www.camh.net/ egambling/issue5/research/griffiths_article.html. Accessed November 13, 2005.

5. Ialomiteanu, A., \& Adlaf, E. (2001). Internet gambling among Ontario adults. Electronic Journal of Gambling Issues. Available at: www.camh.net/egambling/issue5/research/ialomiteanu_adlaf_article.html. Accessed November 13, 2005.

6. Ladd, G.T., \& Petry, N.M. (2002). Disordered gambling among university-based medical and dental patients: a focus on internet gambling. Psychology of Addictive Behaviors 16:76-79.

7. Parke, A., Griffiths, M.D., \& Irwing, P. (2004). Personality traits in pathological gambling: sensation seeking, deferment of gratification and competitive- ness as risk factors. Addiction Research and Theory 12:201-212.

8. Wood, R.T.A., Griffiths, M.D., \& Eatough, V. (2004). Online data collection from videogame players: methodological issues. CyberPsychology \& Behavior 7:511-518.

9. Niemz, K., Griffiths, M.D., \& Banyard, P. (2005). Prevalence of pathological Internet use among university students and correlations with self-esteem, GHQ and disinhibition. CyberPsychology \& Behavior 8:562-570.

10. Griffiths, M.D., Davies, M.N.O., \& Chappell, D. (2004). Demographic factors and playing variables in online computer gaming. CyberPsychology E Behavior 7:479-487.

11. Nower, L., Derevensky, J., \& Gupta, R. (2004). The relationship of impulsivity, sensation seeking, coping and substance use in youth gamblers. Psychology of Addictive Behaviors 18:49-55.

12. Wood, R.T.A., Gupta, R., Derevensky, J.L., et al. (2004). Video game playing and gambling in adolescents. Journal of Child and Adolescent Substance Abuse 14:77-100.

13. Jacobs, D.F. (1986). A general theory of addictions: a new theoretical model. Journal of Gambling Behavior 2:15-31.

14. Blaszczynski, A.P., \& Nower, L. (2002). A pathways model of problem gambling. Addiction 97:487-499.

15. Wood, R.T.A., \& Griffiths, M.D. (2007). A qualitative investigation of problem gambling as an escape-based coping strategy. Psychology and Psychotherapy: Theory, Research and Practise 80:107-125.

Address reprint requests to: Dr. Richard T.A. Wood International Gaming Research Unit Psychology Division Nottingham Trent University Burton Street Nottingham, NG14BU, UK

E-mail: Richard.Wood@ntu.ac.uk 